\title{
Tübinger Akademie für Verhaltenstherapie (TAVT)
}

Die Tübinger Akademie geht ins 5. Jahr ihres Bestehens. Im Oktober 1994 hat die 5. Ausbildungsgruppe ihre Weiterbildung begonnen. Nach wie vor können Gäste nicht an den kontinuierlich angebotenen Abendveranstaltungen teilnehmen, jedoch an den folgenden Blockveranstaltungen, soweit eben Plätze frei sind.

30.9./1.10. Fiedler 19.-21.10. Zimmer/Zimmer 10711.11. Langosch

Verhaltenstherapie bei Zwangskranken

Traum und Phantasie in der Verhaltenstherapie

Soziale Angst und interaktionelle Kompetenz

Paartherapie

Die therapeutische Arbeit mit Anorexie- und Bulimie-

Patientinnen

Biofeedback

Selbstmanagement-Therapie: Verhaltensänderung aus

systematischer Perspektive (Einführungskurs)

Selbstmanagement-Therapie: Verhaltensänderung aus

systematischer Perspektive (Aufbaukurs)

Kognitive und imaginative Verfahren zur Bewältigung trauma-

tischer Erinnerungen bei Opfern sexueller Gewalt

Systematische Beziehungsgestaltung in der Verhaltenstherapie

Diagnostik und Therapie funktioneller Störungen

Organisations- und Rechtsfragen ambulanter Psychotherapie

im Rahmen freiberuflicher psychotherapeutischer Praxis

Persönlichkeitsstörungen und ihre Behandlung

Kognitive Verhaltenstherapie der Depression

Theorie und Praxis verhaltenstherapeutischer Strategien zur

Streßbewältigung unter besonderer Berücksichtigung von

Herz-Kreislauf-Patienten

Interessenten können das Jahresprogramm mit näheren Ausführungen zu den Kursen beim Sekretariat anfordern.

Im Oktober 1995 wird der nächste Ausbildungsgang in Verhaltenstherapie beginnen. Das Auswahlseminar für die neue Gruppe wird am 26. und 27. Juni 1995 stattfinden.

Anfang Oktober wird auch der neue Ausbildungsgang Verhaltenstherapie als Gruppenverfahren beginnen.

Nähere Informationen:

Tübinger Akademie für Verhaltenstherapie

Waldhäuserstr. 48

72076 Tubingen

Tel. (07071)610838

Fax (07071) 760243 
Telefonzeiten: Montag: 10.00-12.00 Uhr

Dienstag bis Freitag: 9.00-12.00 Uhr

Mitteilungen der Verbände 